\title{
Investigation on the Tribological Behaviour of Modified Jatropha Oil with Hexagonal Boron Nitride Particles as a Metalworking Fluid for Machining Process
}

\author{
Norfazillah Talib ${ }^{1, *}$, Ramdziah Md. Nasir ${ }^{2}$, Erween Abd. Rahim ${ }^{1}$ \\ ${ }^{1}$ Precision Machining Research Center (PREMACH), Faculty of Mechanical and Manufacturing Engineering, \\ Universiti Tun Hussein Onn Malaysia, 86400 Batu Pahat, Johor, Malaysia \\ ${ }^{2}$ School of Mechanical Engineering, Universiti Sains Malaysia (Engineering Campus), Seri Ampangan, 14300 Nibong \\ Tebal, Seberang Perai Selatan, Pulau Pinang, Malaysia
}

Received 7 January 2018; accepted 23 January 2018, available online 3 July 2018

\begin{abstract}
Bio-based oil from vegetable oils was recently explored as an alternative solution to petroleum-based oil. However, the application of vegetable oils as metalworking fluids (MWFs) for machining process is still not widespread. The objective of this study was to investigate the tribological behaviour of modified vegetable oils, in comparison with synthetic ester (SE) and crude jatropha oil (CJO). In this study, the CJO was chemically modified via transesterification process to develop modified jatropha oil (MJO5). MJO5 was then blended with the hexagonal boron nitride $(\mathrm{hBN})$ particles at various concentrations ranging between 0.05 to $0.5 \mathrm{wt} . \%$. The friction and wear test was performed using four ball tribotester. An experiment on orthogonal cutting process was carried out to evaluate the machining performances in terms of cutting force, cutting temperature, chip thickness and toolchip contact length. The results reveal that the mixture of $0.05 \mathrm{wt} \%$ of hBN particles in the MJO5-based oil (MJO5a) outperformed the SE in terms of friction and wear. MJO5a showed excellent machining performances by reducing the machining force and temperature, which related to the formation of thinner chips and small tool-chip contact length. MJO5a is the best substitute to SE as sustainable MWFs in the machining operation with regards to the environmental and health concern.
\end{abstract}

Keywords: Modified jatropha oil, hexagonal boron nitride, sustainable metalworking fluid, tribology, orthogonal cutting

\section{Introduction}

Tribological behaviour is related to the sliding motion between two interact surfaces. It includes the principles of friction, wear and lubrication. In the machining process, the tribological behaviour contributes to the reducing in machining energy, power consumption and resource conservation through the reduction in friction and prevent wear [1]. It was reported that $52 \%$ of the worldwide metalworking fluids consumptions is used for the machining purpose [2]. Metalworking fluids (MWFs) plays an important medium to form a thin lubrication film that can resist wear and friction between tool and workpiece. MWFs act as the medium of lubrication, cooling and chip flushing [3].

Wakabayashi et al. [4] indicated that an excellent lubrication film was formed from strong chemical absorptions at the sliding surfaces from an ester lubricant. Ester lubricant comprising a larger molecular chain and branched thus contribute an excellent lubrication behavior [5]. Shahabuddin et al. [6] anticipated that ester lubricant had an outstanding anti-wear and anti-friction ability. The chemical modification process of crude vegetable oil is crucially desirable in enhancing the lubrication and tribological behaviour. The bio-based vegetable oils outperformed the commercial mineral oil by exhibiting excellent lubrication properties in terms of flash point, and viscosity index, non-toxic, low volatility, high coefficient of friction and high biodegradation percentage [7].

Further, the lubrication film of MWFs can be strengthened by the addition of various functions of additives. There have been reports on the tribological behaviours of lubricating oil on hexagonal boron nitride (hBN) as an additive. $\mathrm{hBN}$ particles is a green solid lubricant that is safe to handle, non-toxic and no limitations on its operational used which has good thermal stability and high thermal conductivity [8]. Nguyen et al. [9] reported that the addition of boron nitride powder in MWFs enhances the lubrication behaviour. They found that the flank and central wear of the ball mill had reduced with the addition of $\mathrm{hBN}$ particles in the lubricant. Besides, Abdullah et al. [10] indicated that the presence of hBN particles in engine oil reduces the sliding friction into the rolling friction, resulting in the reduction of the coefficient of friction 
(COF) and wear rate. However, there is a limited study that discussed the effects of the tribological behaviour on machining performances. Therefore, this study focuses on the influence of tribological behaviour in machining performances of various types of modified jatropha oils as MWFs.

\section{Methodology}

\subsection{Lubricant preparation}

In this experiment, the crude jatropha oil (CJO) was modified and enhanced via the chemical process to develop modified jatropha oil (MJO5). The MJO5 was developed via transesterification process of jatropha methyl ester (JME) and trimethylolpropane (TMP) at the molar ratio of JME:TMP; 3.5:1 with sodium methoxide, $\mathrm{CH}_{3} \mathrm{ONa}$ as the catalyst. This process altered the long carbon chain of CJO into the long, complex and branched carbon chain of MJO5. It was indicated from the previous studies that MJO5 exhibits excellent machining performances $[11,12]$. MJO5 was mixed with hBN particles at various concentrations ranging between 0.05 to $0.5 \mathrm{wt} . \%$ as shown in Table 1 . The sizes of hBN particles were in between 2 to $5 \mu \mathrm{m}$. The physicochemical properties of $\mathrm{hBN}$ particles were presented in Table 2 . The prepared lubricants were then compared with commercial synthetic ester (SE) and CJO.

Table 1: Lubricant samples

\begin{tabular}{ll}
\hline Symbol & \multicolumn{1}{c}{ Descriptions } \\
\hline SE & Synthetic ester \\
CJO & Crude jatropha oil \\
MJO5 & Modified jatropha oil \\
MJO5a & MJO5+0.05wt.\% hBN \\
MJO5b & MJO5+0.1wt.\% hBN \\
MJO5c & MJO5+0.5wt.\% hBN \\
\hline
\end{tabular}

Table 2: Physicochemical properties of hBN particles

\begin{tabular}{ll}
\hline \multicolumn{1}{c}{ Physicochemical properties } & Value \\
\hline Density $(\mathrm{g} / \mathrm{cm} 3)$ & 2.3 \\
Young's modulus $(\mathrm{MPa})$ & $20-102$ \\
Thermal expansion coefficient $\left(10-6 /{ }^{\circ} \mathrm{C}\right)$ & 1 \\
Thermal conductivity $(\mathrm{cal} / \mathrm{cm} . \mathrm{sec} . \mathrm{K})$ at & 0.08 \\
293K, directional average & \\
\hline
\end{tabular}

\subsection{Friction and wear test}

Friction and wear test was conducted by four balls tribotester machine. The testing was done according to ASTM D4172 to determine the wear scar diameter (WSD) and COF. The normal load used was at load $392 \mathrm{~N}$, with $1200 \mathrm{rpm}$ rotational speed and was regulated at temperature $75{ }^{\circ} \mathrm{C}$ for 1 hour. The WSD of the bottom three balls was measured by the optical microscope and COF was determined from the software.

\subsection{Orthogonal cutting process}

The orthogonal cutting process was carried out through NC lathe machine at three levels of cutting speeds as shown in Table 3. AISI 1045 has been chosen

Table 3: Machining conditions

\begin{tabular}{ll}
\hline Description & Values \\
\hline Cutting speed, $V_{c}(\mathrm{~m} / \mathrm{min})$ & $350,450,550$ \\
Feed rate, $f_{r}(\mathrm{~mm} / \mathrm{rev})$ & 0.12 \\
Width of cut, $d(\mathrm{~mm})$ & 2 \\
Tool rake angle, $\alpha\left(^{\circ}\right)$ & 5 \\
MQL input pressure $(\mathrm{MPa})$ & 0.4 \\
Lubricant flowrate $(1 /$ hour $)$ & 0.16 \\
Nozzle diameter $(\mathrm{mm})$ & 2.5 \\
Nozzle distance $(\mathrm{mm})$ & 8 \\
Nozzle angle $\left(^{\circ}\right)$ & 45 \\
\hline
\end{tabular}

Table 4: Mechanical and thermal properties of AISI 1045

\begin{tabular}{ll}
\hline \multicolumn{1}{c}{ Mechanical properties } & \multicolumn{1}{c}{ Value } \\
\hline Density $(\mathrm{g} / \mathrm{cm} 3)$ & $7.7 .-8.03$ \\
Poisson ratio & $0.27-0.3$ \\
Elastic modulus (Gpa) & $190-210$ \\
Yield strength (Mpa) & 505 \\
Tensile strength (Mpa) & 585 \\
Hardness (HB) & 170 \\
Thermal expansion $\left({ }^{\circ} \mathrm{C}\right)$ & 15.1 \\
\hline
\end{tabular}
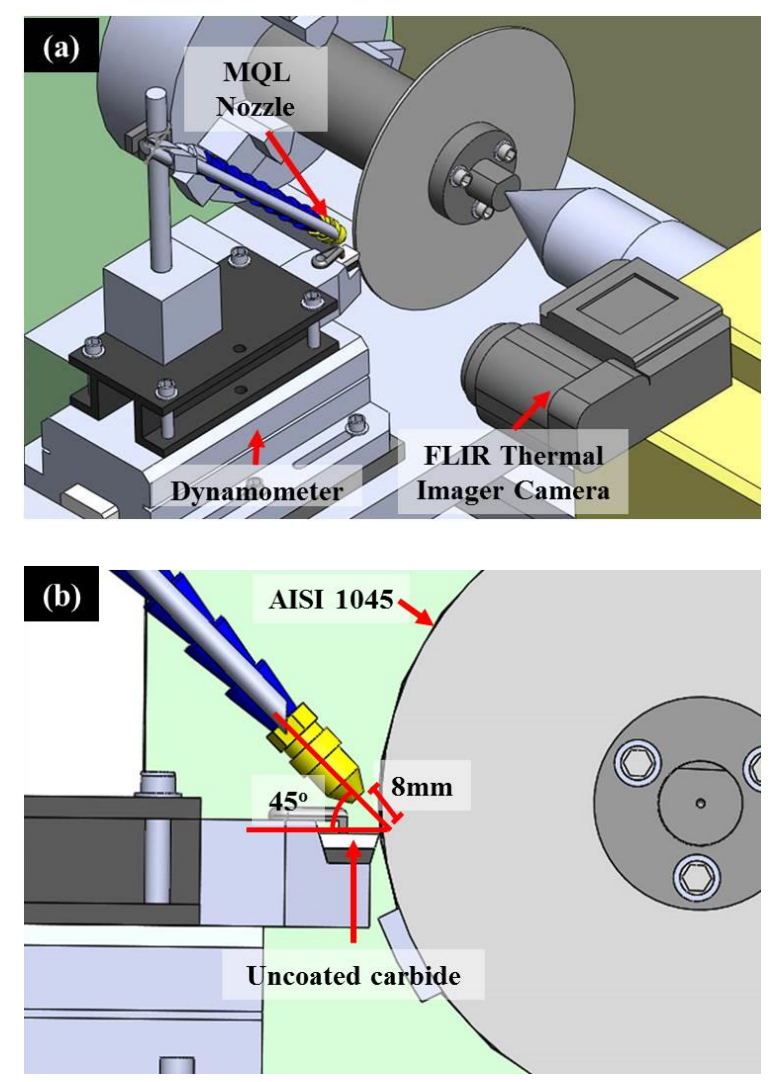

Fig. 1: (a) Orthogonal cutting set up (b) The nozzle location

as the workpiece with a diameter and thickness of 150 $\mathrm{mm}$ and $2 \mathrm{~mm}$, respectively. Table 4 represents the 
mechanical and thermal properties of AISI 1045. The lubricant was supplied via minimum quantity lubrication (MQL) method. The location and orientation of the nozzle are shown in Figs. 1(a) and 1(b). The uncoated carbide insert, SPGN120308 type K313 was used as the cutting tool and mounted at the tool holder. Both insert and tool holder was fixed on the dynamometer, Kistler 9257BA. The dynamometer was connected to the multichannel amplifier, Kistler 5070 and the cutting force data was recorded by using the Dynaware software. The maximum cutting temperature was captured via FLIR T640 thermal imager camera. The emissivity value was set at a constant value. Ten samples of the deformed chip from the machining process were collected. The average value of the chip thickness was measured via the tapered nosed micrometre. The tool insert was analysed through tool maker's microscope in order to measure the tool-chip contact length.

\section{Results and Discussion}

\subsection{Wear scar diameter and coefficient of friction}

Table 5 displayed the result of WSD and COF. MJO5 showed better tribological behaviour compare to SE due to the small WSD and low COF of $1.2465 \mathrm{~mm}$ and 0.0222 , respectively. It can be seen that the addition of $0.05 \mathrm{wt} . \%$ of hBN in MJO5 (MJO5a) had $4 \%$ and $3 \%$ reduction of WSD and COF compared to MJO5. The

Table 5: Tribological properties

\begin{tabular}{lcc}
\hline Sample & $\begin{array}{c}\text { Wear scar diameter, } \\
\text { WSD }(\mathrm{mm})\end{array}$ & $\begin{array}{c}\text { Coefficient of } \\
\text { friction, COF }\end{array}$ \\
\hline SE & 1.5529 & 0.0895 \\
CJO & 0.6823 & 0.0520 \\
MJO5 & 1.2465 & 0.0222 \\
MJO5a & 1.1860 & 0.0217 \\
MJO5b & 1.4426 & 0.0257 \\
MJO5c & 1.5021 & 0.0287 \\
\hline
\end{tabular}
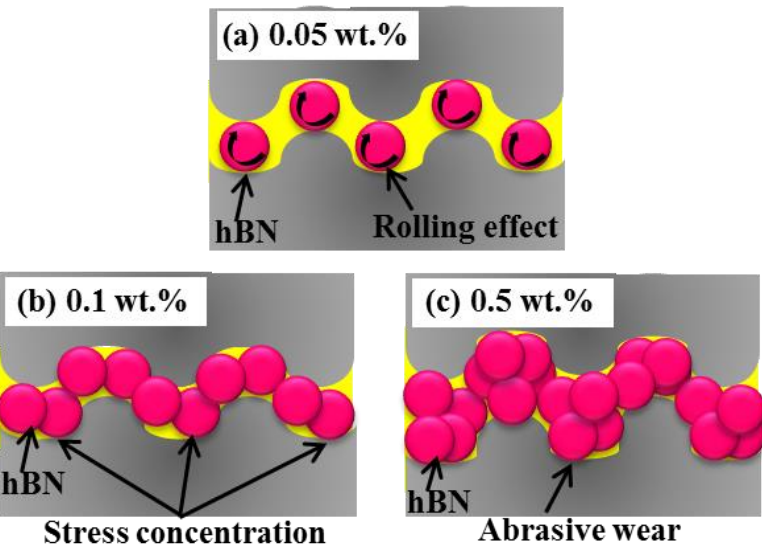

Fig. 2: Schematic diagram of lubrication film of MJO samples with various concentration of $\mathrm{hBN}$ particles [12] WSD and COF of MJO5a were recorded at $1.186 \mathrm{~mm}$ and 0.0217 . The presence of $0.05 \mathrm{wt} . \%$ of $\mathrm{hBN}$ particles provides a thin lubrication film that allows the particles to change from sliding friction to the rolling friction as shown in Fig. 2(a). Further, the results showed that the WSD and COF increased with the increasing amount of hBN concentrations $(0.1 \mathrm{wt} . \%$ and $0.5 \mathrm{wt} . \%)$. This is because of the stress concentration increases gradually with an increase in the $\mathrm{hBN}$ concentrations as shown in Figs. 2(b) and 2(c). The hBN particles acted as the abrasive particles which caused an increase in friction and wear at the contact surfaces [12].

\subsection{Cutting force}

It can be observed from Fig. 3 that MJO5 shows a reduction between 8 to $12 \%$ of the cutting force when compared to SE. It was expected that the modified lubricant, MJO5 has long, complex and branched of molecular chain that affect the lubrication properties [12]. MJO5 provide superior anti-wear and anti-friction ability and formed excellent lubrication film between the tool and workpiece. Meanwhile, it can be observed that the CJO recorded the higher cutting force when compare with MJO5 and SE. The CJO has low oxidative and thermal stability that reducing machining efficiency. Low oxidative stability affects by thickening the oil thereby reduced the lubricating behaviour [5]. Moreover, the mixture of $0.05 \mathrm{wt} \%$ of $\mathrm{hBN}$ in MJO5 (MJO5a) reduces the cutting force. This indicates that the lubrication film formed from MJO5a has excellent lubricating performance. The cutting forces recorded by using MJO5a had reduced between 2 to $3 \%$ when compared to MJO5. The $0.05 \mathrm{wt} . \%$ of $\mathrm{hBN}$ tends to separate the tool and workpiece during the machining process thus contributes in reducing the sliding friction. The $\mathrm{hBN}$ particles had altered the sliding friction into the rolling friction [12]. However, the increment of $\mathrm{hBN}$ particles in MJO5 causes abrasive wear to occur at the contact surfaces. This was due to the rubbing process from the $\mathrm{hBN}$ particles at the contact surfaces that increased the friction between tool and workpiece [13].

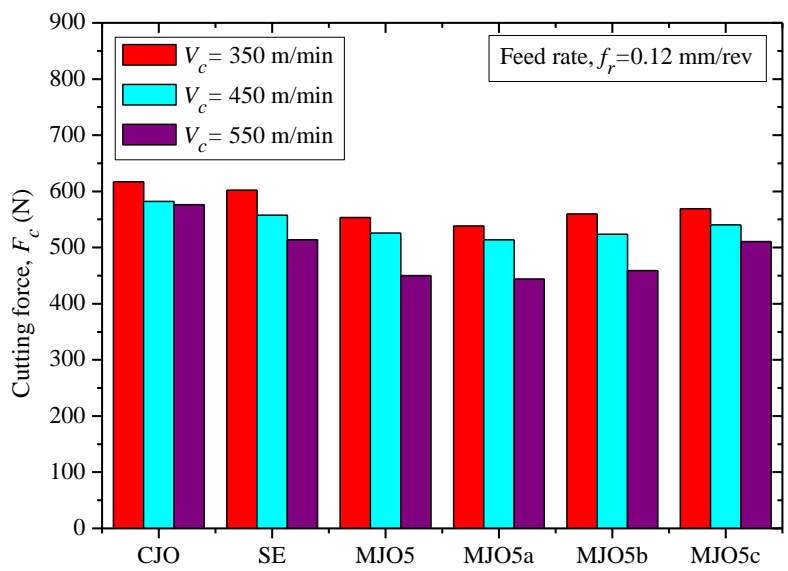

Fig. 3: Cutting force at $f_{r}=0.12 \mathrm{~mm} / \mathrm{rev}$

\subsection{Cutting temperature}


Fig. 4 shows the maximum cutting temperature captured during the orthogonal cutting process. The modification process of CJO significantly improved the performances of MJO5. It can be observed that the cutting temperature generated by MJO5 reduces in the range between 7 to $8 \%$ when compared to SE. Besides, the recorded cutting temperature of MJO5 also showed a huge discrepancy between 13 to $15 \%$ compared to CJO. From the result, it shows that the friction and wear behaviour of MJO5 was able to withstand high operating temperature, thus maintain its lubrication film. This was due to the formation of the long, complex and branched of molecular chain in MJO5. Thus, lowering the heat generated at the tool-workpiece interfaces. Moreover, the maximum cutting temperature of CJO was due to the high percentage of unsaturated fatty acids (UFA) contains in the CJO between 60 to $80 \%$ that accelerate with a lower melting point [7]. The carbon chains of CJO are easily broken with the existing of the double bond in UFA. Thus, the lubrication film of CJO is unable to resist high operating temperature.

Furthermore, the mixture of $0.05 \mathrm{wt} . \%$ of $\mathrm{hBN}$ in MJO5 (MJO5a) decreased the maximum cutting temperature. This was because of the solid particle in MJO5a tends to form a lubrication film which prevents adhesion. The percentage reduction of cutting temperature for MJO5a was between 3 to $6 \%$ compare to MJO5. This was due to the reduction in sliding friction and less interaction between contact surfaces of tool and workpiece [12]. Apart from that, the increment of hBN particles in MJO5b and MJO5c had increased the cutting temperature. This might be attributed with the enhancing of abrasive wear due to the presence of excessive hBN particles [13]. The increment of abrasive wear accelerates the cutting temperature.

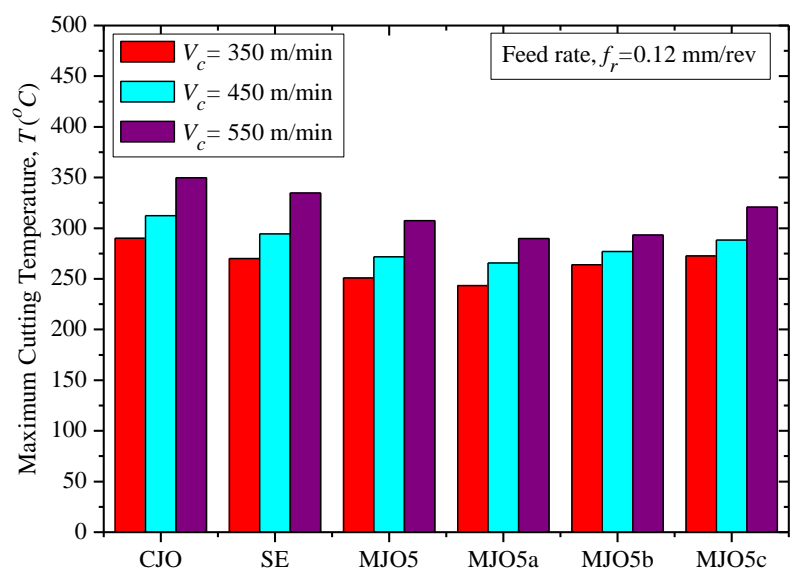

Fig. 4: Cutting temperature at $f_{r}=0.12 \mathrm{~mm} / \mathrm{rev}$

\subsection{Chip thickness}

Fig. 5 indicates the average thickness of chips after the orthogonal cutting process obtained at various cutting speeds. The thickness of chip decreased as the cutting speed increased due to the reduction in material removal per revolution [11]. The chip characteristics significantly

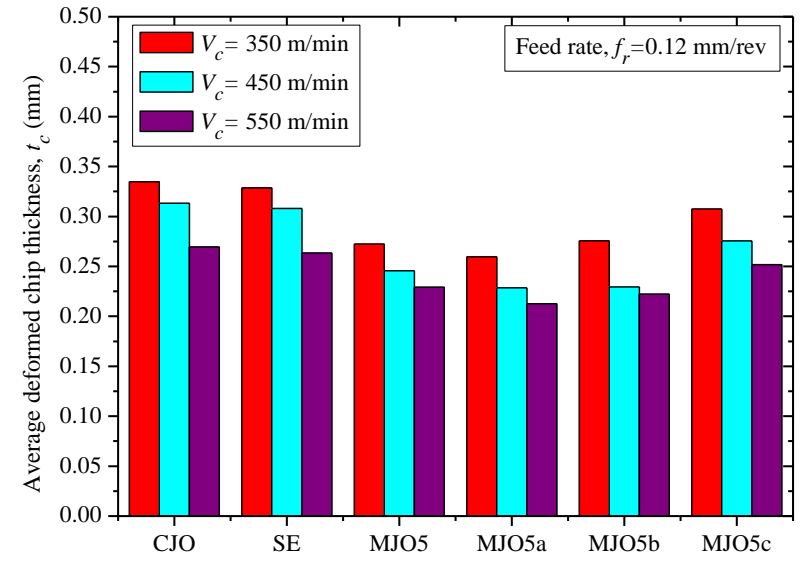

Fig. 5: Average deformed chip thickness at $f_{r}=0.12 \mathrm{~mm} / \mathrm{rev}$

affected from the heat generated during the machining process [14]. It was recorded that the thickness of MJO5's chip had reduced between 13 to $20 \%$ compared to SE. This indicates that the lubrication film formed had prevented the adhesion from occurring. Thus, the friction at the tool and workpiece interfaces is reduced. The long, complex and branched of the molecular chain of MJO5 exhibit superior lubrication and tribological behaviour. Meanwhile, the CJO exhibits thicker chip thickness due to the lack of lubrication film formed. This failure resulted in the less thermal and oxidative stability of the crude oil due to the presence of UFA in the lubricant molecular chain.

Besides, the mixture of $0.05 \mathrm{wt} . \% \mathrm{hBN}$ in MJO5 (MJO5a) resulted in thinner chips. The reduction of the chip thickness between 5 to $7 \%$ was recorded by MJO5a compared to MJO5. The lubrication film formed from MJO5a had an excellent anti-wear and anti-friction ability [12]. Additionally, the increment of excessive hBN particles in MJO5b and MJO5c are detrimental to the tribological behaviour. The friction between toolworkpiece interfaces was directly proportional to the chip thickness.

\subsection{Tool chip contact length}

Fig. 6 showed the tool-chip contact length at various cutting speeds. The tool-chip contact length was observed at the tool rake faces. Fig. 7 shows the tool-chip contact length observed at feed rate, $f_{r}=0.12 \mathrm{~mm} / \mathrm{rev}$ and cutting speed, $V_{c}=550 \mathrm{~mm} / \mathrm{min}$. It was noted that the tool-chip contact length was influenced by the cutting force value [15]. The cutting force decreased as the cutting speed increased, thus decreasing the tool-chip contact length. This was due to the reduction of material per revolution. However, the tool-chip contact length increased along with the increase of feed rate. This was due to the greater chip loaded as the feed rate is increased. It can be observed that CJO recorded wider tool-chip contact length compared to other samples as shown in Fig. 7(a). This proves that the lubrication film of CJO is unable to withstand high friction and high temperature operation. 
The modification of CJO is crucially important in order to enhance its performance. From the results, the tool-chip contact length of MJO5 had reduced between 2 to 3\% compared to SE. It can be seen from Figs. 7(b) and 7(c), the tool-chip contact length of MJO5 is much smaller than SE.

Moreover, MJO5a shows an encouraging improvement as shown in Fig. 7(d). The tool-chip contact length has reduced between 2 to $3 \%$ compared to the MJO5. The hBN particles help in strengthen the lubrication film thus reducing the sliding area between tool and workpiece. However, the tool-chip contact length increased as the hBN particles increased as shown in Figs. 7(e) and 7(f). This is because of the increment of cutting force values of MJO5b and MJO5c that relates to the increase of the contact area.

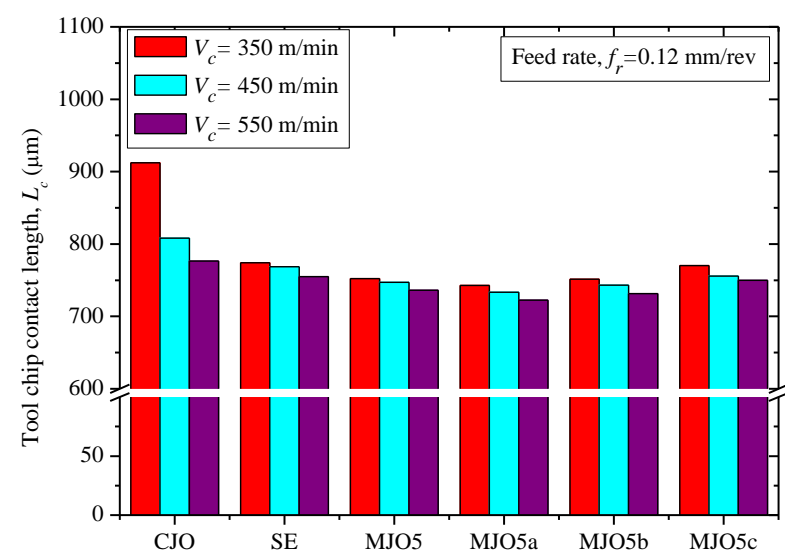

Fig. 6: Tool-chip contact length at $f_{r}=0.12 \mathrm{~mm} / \mathrm{rev}$

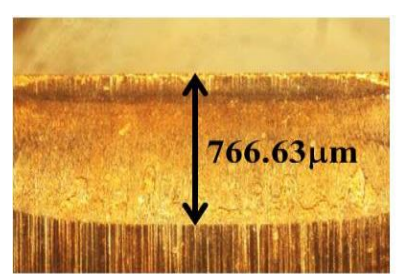

(a) $\mathrm{CJO}$

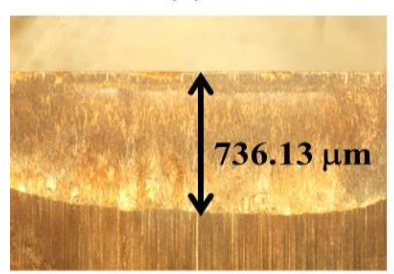

(c) $\mathrm{MJO5}$

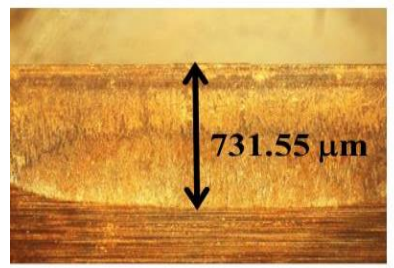

(e) $\mathrm{MJO5b}$

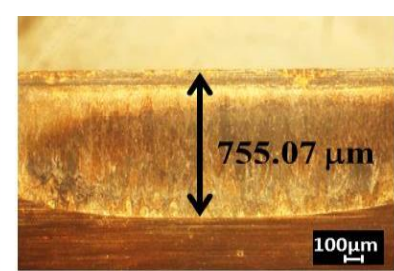

(b) SE

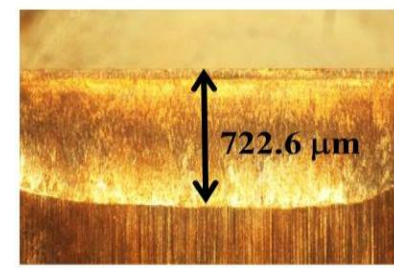

(d) MJO5a

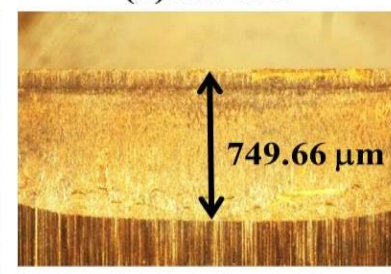

(f) $\mathrm{MJO5c}$
Fig. 7: Optical images of tool chip contact length at feed rate, $f_{r}=0.12 \mathrm{~mm} / \mathrm{rev}$ and cutting speed, $V_{c}=550 \mathrm{~mm} / \mathrm{min}$

\section{Summary}

Based on the analysis results, it can be determined that the tribological behaviour of lubricant significantly affect the machining performances. The chemical modification of the CJO is crucially essential in enhancing its lubrication and tribological behaviour. Moreover, the addition of $\mathrm{hBN}$ particles as an additive in the lubricant promised a better tribological behaviour. Hence, the following conclusions can be drawn from this study;

(i) MJO5 exhibit superior WSD and COF at 1.2465 $\mathrm{mm}$ and 0.0222 , respectively. MJO5 developed excellent lubrication film that resulted in excellent machining performances. It shows that MJO5 had reduced 8 to $12 \%$ of cutting force, 7 to $8 \%$ cutting temperature, 13 to $20 \%$ of chips thickness and 2 to $3 \%$ tool-chip contact length compared to commercial SE.

(ii) The mixture of $0.05 \mathrm{wt} . \%$ of $\mathrm{hBN}$ in MJO5a significantly improved the tribological behaviour in terms of wear and friction thus resulted in excellent machining performances. The WSD and COF were recorded at $1.186 \mathrm{~mm}$ and 0.0217 . MJO5a formed a lubrication film that can resist friction and heat generated thus, reducing 2 to $3 \%$ of cutting force, 3 to $6 \%$ of cutting temperature, 5 to $7 \%$ of chip thickness and 2 to $3 \%$ of tool-chip contact length compared to MJO5.

(iii) The excessive amount of $\mathrm{hBN}$ particles in $\mathrm{MJO5b}$ and MJO5c reduced the lubrication and tribological behaviour. The contact surfaces suffered from high friction increased, resulted in poor machining efficiency in terms of cutting force, cutting temperature, chip thickness and toolchip contact length.

(iv) It can be concluded that MJO5a is the best substitute to SE as sustainable MWFs in the machining operation with regards to the environmental and health concern.

\section{Acknowledgement}

The authors would like to express their gratitude to the Malaysian Ministry of Education and Universiti Tun Hussein Onn Malaysia for their financial support via Fundamental Research Grant Scheme (Vot 1467) and SLAB financial scheme, respectively. Further, this paper was partly sponsored by Centre for Graduate Studies, UTHM.

\section{References}

[1] Rahim, E.A. and Sasahara, H. A study of the effect of palm oil as MQL lubricant on high speed drilling of titanium alloys. Tribology International, Volume 44, No. 3, (2011), pp. 309-317.

[2] Marksberry, P.W. and Jawahir, I.S.A. A comprehensive tool-wear/tool-life performance model in the evaluation of NDM (near dry 
machining) for sustainable manufacturing. International Journal of Machine Tools and Manufacture, Volume 48, No. 7-8, (2008), pp. 878-886.

[3] Sapian, N.F., Omar, B., Hamdi, M. and Shukor, A. Integrated Mechanical Pulse Jet Coolant Delivery System Performance for Minimal Quantity Lubrication. International Journal of Integrated Engineering, Volume 2, No.1, (2010), pp. 53-68.

[4] Wakabayashi, T., Suda, S., Inasaki, I., Terasaka, K., Musha, Y. and Toda, Y. Tribological action and cutting performance of MQL media in machining of aluminum. Annals of the CIRP, Volume 3, (2007), pp. 97-100.

[5] Arbain, N.H. and Salimon, J. Synthesis and characterization of ester trimethylolpropane based jatropha curcas oil as biolubricant base stocks. Journal of Science and Technology, (2011), pp. 4758.

[6] Shahabuddin, M., Masjuki, H.H., Kalam, M.A., Bhuiya, M.M.K. and Mehat, H. Comparative tribological investigation of bio-lubricant formulated from a non-edible oil source (Jatropha oil). Industrial Crops and Products, Volume 47, (2013), pp. 323-330.

[7] Salimon, J., Abdullah, B.M., Yusop, R.M. and Salih, N. Synthesis, reactivity and application studies for different biolubricants. Chemistry Central Journal., Volume 8, (2014), pp. 1-11.

[8] Reeves, C.J., Menezes, P.L., Lovell, M.R. and Jen, T.C. The size effect of boron nitride particles on the tribological performance of biolubricants for energy conservation and sustainability. Tribology Letters, Volume 51, No. 3, (2013), pp. 437-452.

[9] Nguyen, T.K., Do, I. and Kwon, P. A tribological study of vegetable oil enhanced by nano-platelets and implication in MQL machining. Journal of Precision Engineering and Manufacturing, Volume 13, No. 7, (2012), pp. 1077-1083.

[10] Abdullah, M. I.H.C., Abdollah, M.F., Amiruddin, H., Tamaldin, N. and Nuri, N.R.M. Effect of $\mathrm{hBN} / \mathrm{Al}_{2} \mathrm{O}_{3}$ nanoparticle additives on the tribological performance of engine oil. Jurnal Teknologi, Volume 3, (2014), pp. 1-6.

[11] Talib, N. and Rahim, E.A. The effect of tribology behavior on machining performances when using bio-based lubricant as a sustainable metalworking fluid. Procedia CIRP, Volume 40, (2016), pp. 504508.

[12] Talib, N., Nasir, R.M. and Rahim, E.A. Tribological behaviour of modified jatropha oil by mixing hexagonal boron nitride nanoparticles as a bio-based lubricant for machining processes. Journal of Cleaner Production, Volume 147, (2017), pp. 360378.

[13] Peng, D. and Chen, C. Size effects of $\mathrm{SiO}_{2}$ nanoparticles as oil additives on tribology of lubricant. Industrial Lubrication and Tribology, Volume. 2, (2010), pp. 111-120.

[14] Abdulkareem, S., Rumah, U. J. and Adaokoma, A.
Optimizing Machining Parameters during Turning Process. International Journal of Integrated Engineering, Volume 3, No.1, (2011), pp. 23-27.

[15] Rahim, E.A., Ibrahim, M.R., Rahim, A.A., Aziz, S. and Mohid, Z. Experimental investigation of minimum quantity lubrication (MQL) as a sustainable cooling technique. Procedia CIRP, Volume 26, (2015), pp. 351-354. 